\title{
Siyah Alaca Siğırlarda Zaman Serileri ile Farklı Laktasyon Eğrisi Modellerinin Karşılaştırılması
}

\section{Emine ÇETİ TEKE ${ }^{1}$, Hikmet ORHAN $2^{8}$}

Akdeniz Üniversitesi Ziraat Fakültesi Zootekni Bölümü Antalya, Turkey, ${ }^{2}$ Süleyman Demirel Üniversitesi Tıp Fakültesi Biyoistatistik ve Tıbbi Bilişim Anabilim Dalı, Isparta, Turkiye

${ }^{1}$ https://orcid.org/0000-0003-0542-7065, 2https://orcid.org/0000-0002-8389-1069

$\varangle$ : hikmetorhan@sdu.edu.tr

\section{ÖZET}

Bu çalışmanın amacı Siyah Alaca süt sığırlarında mevcut süt verimi kayıtlarından yararlanarak ileriki dönem süt veriminin daha az hataya sahip uygun modellerle tahmin edilmesi ve "Laktasyon eğrisi tahmininde kullanılacak olan Zaman serileri metodu, klasik metotlardan daha güvenilir sonuçlar vermekte midir?" sorusuna yanıt aramak amaçlanmıştır. Bu amaçla laktasyon eğrisi tahmininde Brody, Wood, Cobby \& Le Du ve zaman serisi modelleri kullanılmıştır. Araştırma materyali 2009-2011 yıllarında Burdur ilinde yürütülmüş projeden derlenen 80 adet siyah alaca ineğe ait 305 günlük 4 laktasyon kaydından elde edilen verilerden sağlanmıştır. Laktasyon eğrisi modellerinde zaman serisi metodu Wood modeline göre süt verimini gerçek verim değerlerine daha yakın tahmin etmiştir. Bütün laktasyonlarda zaman serisi model artıkları arasında birinci dereceden ardışık bir ilişki olmadığı, artıklarının rasgele dağıldığı, modelin artıklarının birbirinden bağımsız ve homojen olduğu ve modelin süt verimi tahminine uygun olduğu görülmüştür. Zaman serisi metodunun laktasyon eğrisi modellemede kullanılan geleneksel yöntemlere iyi bir alternatif olduğu söylenebilir.

\section{Comparison of Time Series with Different Lactation Curve Models in Holstein Cattle}

\section{ABSTRACT}

The aim of this study was to estimate the future milk yield with suitable models sustaining fewer errors by using the existing milk yield records in Holstein dairy cattle and to find the answer for the question of "does the Time series method used in the estimation of the lactation curve give more reliable results than the classical methods?" For this purpose, Brody, Wood, Cobby \& Le Du and time series models were used for estimating the lactation curve. The research data was obtained from 4 lactation records of 305 days of 80 black dairy cattle compiled from the project conducted in Burdur province between 2009-2011. In the model of lactation curves, the time series method predicted that the milk yield was closer to the actual yield values than the gamma model. In all lactations, it was seen that there were no consecutive relations among the time series model residues, that the residues were randomly distributed, the residues of the model were independent and homogenous, and that the model was suitable for milk production. It can be concluded that the time series method was a good alternative to the traditional methods used in modeling of lactation curve.

\section{Araştırma Makalesi}

\author{
Makale Tarihçesini \\ Geliş Tarihi $\quad: 27.07 .2020$ \\ Kabul Tarihi : 01.10 .2020
}

Anahtar Kelimeler

Süt sığırcılığı

Wood

ARIMA

Zaman serileri

Matematiksel model

\section{To Cite: $\quad$ Çetin Teke E, Orhan H 2021. Siyah Alaca Sığırlarda Zaman Serileri ile Farklı Laktasyon Eğrisi Modellerinin Karşılaştırılması. KSÜ Tarım ve Doğa Derg 24 (3): 679-688. https://doi.org/10.18016/ksutarimdoga.vi.774674. \\ To Cite: Cetin Teke E, Orhan H 2021. Comparison of Time Series with Different Lactation Curve Models in Holstein Cattle. KSU J. Agric Nat 24 (3): 679-688. https://doi.org/10.18016/ksutarimdoga.vi.774674.}

\section{GİRIŞ}

Süt sığırcıllğg, süt ve süt ürünleri üretimini ve besi materyalini sağladığından pek çok ülke tarafından önemli görülen bir üretim alanıdır. Türkiye'de büyük baş hayvancılığın bir bölümünü süt sığırcılığı oluşturur (Murat ve Sakarya 2012). Ülkemizde süt 
sığırcılığının bir bölümünü oluşturan kültür ırkının büyük bir kısmı sütçü özelliğiyle bilinen Siyah-Alaca ırktan oluşmaktadır. Siyah-Alaca ırkı simental, esmer ve jersey irkları takip etmektedir (Anonim 2017).

Genetik ve çevresel faktörlerin etkisiyle şekillenen, buzağılama ile başlayıp kuruya çıkma ile son bulan süt verimindeki değişiklikler laktasyon eğrisi (Lactation curve) olarak tanımlanmaktadır (Orhan ve Kaygisız 2002). Süt hayvanları için ortalama 305 gün olarak belirlenen laktasyon süresi bakım ve beslenmeye bağlı olarak değişebilir (Keskin ve Tozluca 2004). Laktasyon eğrisi, süt işletmelerinde süt üretiminin ekonomisi üzerinde etkisi olan besleme, çiftleşme, ıslah ve itlaf gibi kararları almak için yetiştiriciler için değerli bir araç olabilir. Kontrol günü kayıtlarına dayalı laktasyon eğrisinin incelenmesi, eksik gözlem değerleri ve süt veriminin tahmin edilmesinde yardımcıdır. Laktasyon eğrilerinin şekli matematiksel model eşitliklerindeki katsayıları ile tanımlanabilir. $\mathrm{Bu}$ katsayılar istenen şekillere sahip laktasyonların seçimi için önemlidir. Sürdürülebilir süt üretimi için laktasyon eğrisinin buzağılamadan zirveye süt veriminde hızlı bir artış ve ardından zirveden yavaş bir düşüş göstermesi istenir (Teke ve ark. 2020).

Gelişmiş ülkelerdeki hayvansal üretimle yarışabilmek, ülkemizdeki bireylerin süt ihtiyaçlarını karşılayabilmek amacıyla süt verimi yüksek hayvanların seçilebilmesi için hayvanların süt verimlerini tahmin etmeyi sağlayan modellerin oluşturulması önemlidir. Bu çalışmada süt veriminin daha sonraki dönemlerde nasıl olabileceğini tahmin etmek için klasik metotlar (Brody, Wood, Cobby ve Le $\mathrm{Du})$ alternatif olarak Zaman serileri metodu kullanılarak, elde edilen sonuçlar karşılaştırılmalı olarak incelenmiştir. Siyah Alaca süt sığırlarının laktasyon eğrisinin tahmininde kullanılacak olan Zaman serileri metodu, klasik metotlardan daha güvenilir sonuçlar vermekte midir? Sorusunun cevabı araştırılmıştır.

\section{MATERYAL ve METOD}

Çalışmada, Burdur ilinde 2009-2011 yıllarında yürütülmüş, TUBİTAK 1090336 nolu projeden derlenmiş günlük sağım kayıtlarının kaydedildiği kısmi veriler kullanılmıştır. Veriler 80 adet Siyah alaca sığırın 1-4 laktasyon kayitlarından oluşmaktadır. Her bir laktasyon kaydında 305 günlük süt verimleri kullanılmıştır. Daha uzun sağım süresine sahip olan hayvanların 305 günden sonraki kayıtları dâhil edilmemiştir. Modellerin oluşturulmasında sığırların günlük süt verimleri bağımlı değişken, kontrol günü bağımsız değişken olarak alınmıştır.

\section{Matematiksel Fonksiyonlar}

Doğrusal olmayan klasik bir eğri, laktasyon süresinin temsili grafiğidir. Araştırmacılar süt verim verileri ile matematiksel fonksiyonların eşleşmesiyle; laktasyon eğrisinin tanımlanabileceği ve bazı önemli performans özelliklerine ilişkin tahminler elde edileceğini bildirmişlerdir (France ve Kebreab 2008, Teke ve ark. 2020). Araştırmada kullanılan modeller ve fonksiyonlar Çizelge 1'de verilmiştir.

Zaman serisi analizi, laktasyon eğrilerini modellemek ve geleceği tahmin etmek için kullanılan başka bir yöntemdir.

Çizelge 1. Araştırmada kullanılan modeller

Table 1. Models used in the research

\begin{tabular}{lll}
\hline Metodoloji (Methodology) & Modeller (Models) & Denklem (Equation)* \\
\hline (Brody ve ark. 1924) & M1 (Exponential decline function) & $Y_{t}=\alpha e^{-b t}-\alpha e^{-c t}+\varepsilon_{t}$ \\
(Wood 1967) & M2 (Incomplete gamma function) & $Y_{t}=\alpha t^{b} e^{-c t}+\varepsilon_{t}$ \\
(Cobby ve Le Du 1978) & M3 (Linear decline function) & $Y_{t}=\alpha-b t-\alpha e^{-c t}$ \\
\hline
\end{tabular}

${ }^{\star} Y_{t}$ :Günlük süt verimi; t: t. kontrol günü; $\varepsilon_{t}$ :hata (artık); a,b,c: regresyon katsayıları

\section{Zaman Serileri}

Zaman serileri, tahmin edilecek verinin geçmiş değerleri veya beklenmedik değişmelerin mevcut ve geçmiş değerlerinin bileşimidir (Yıldız 2009). Bir zaman serisi analizi yapmadan önce, serinin zaman içinde durağan olup olmadığını incelemek gerekir (Göktaş 2005). Durağanlık, bir sürecin olasıllk yapısının zaman içindeki değişmezliği anlamına gelir. (Kadılar 2005). Durağan bir serinin beklenen değeri ve varyansı sabit, kovaryansı zamandan bağımsız gecikme sayısına bağlı olmalıdır. Durağanlık koşullari; Ortalama; $E\left(Y_{t}\right)=\mu$, varyans; $\operatorname{Var}\left(Y_{t}\right)=$ $E\left(Y_{t}-\mu\right)^{2}=\sigma^{2}, \quad$ kovaryans; $\quad \gamma_{k}=E\left[\left(Y_{t}-\mu\right)\left(Y_{t-k}-\right.\right.$ $\mu)]=\sigma^{2}$ (Bozkurt 2013).
Zaman serisi analizini uygulamak için, seri durağan olmalı ve tahmin modeli hata terimleri beyaz gürültü özelliğini sağlamalıdır. Zaman serisi analizinde durağanlığı test etmek için, otokorelasyon fonksiyonu (ACF), kısmi otokorelasyon fonksiyonu (PACF) ve birim kök testi (ADF) sonuçları incelenir. Beyaz gürültü serisinin tüm gecikmelerinde otokorelasyon ya da kısmi otokorelasyon değerleri önemsizdir (Kadılar 2005, Akdi 2010). Seri $\varepsilon_{t} \approx i i d\left(0, \sigma^{2}\right)$ dağılımına sahip ise beyaz gürültü (white noise), $\varepsilon_{t} \approx i i d\left(0, \sigma^{2}\right)$ sahip değilse rassal yürüyüş serisidir. Durağan olmayan stokastik süreçlerin modellenebilmesi için serinin durağan olması gereklidir. Bunun yüzden durağanlığı 
sağlamak için serinin gereken miktarda farkı alınmalıdır. Farkı alınarak durağanlaştırılan seriler ARIMA modelleriyle gösterilmektedir (Wade ve ark. 1993, Göktaş 2005).

Otoregresif entegre hareketli ortalama süreci (ARIMA)

ARMA(p,q) genel denklemi (Eşitlik 1), $\nabla$; fark alma operatörü ve $Y_{t}$ yerine $Y_{t}$ 'nin $d$. mertebeden farkı alınmış seri yazılırsa, $W_{t}=\nabla^{d} Y_{t}$ şeklinde ARIMA denklemine (Eşitlik 2) ulaşılır. ARIMA (p,d,q) modeli; d. dereceden farkı alınmış p. dereceden $A R$ ve $q$. dereceden MA modelinin kombinasyonu olarak tanımlanır. ARMA (p, q);

$Y_{t}=\delta+\phi_{1} Y_{t-1}+\phi_{2} Y_{t-2}+\ldots+\phi_{p} Y_{t-p}+\varepsilon_{t}+\theta_{1} \varepsilon_{t-1}$

$+\theta_{2} \varepsilon_{t-2}+\ldots . \theta_{q} \varepsilon_{t-q}$

$Y_{t}=\sum_{i=1}^{p} \phi_{p} Y_{t-i}+\varepsilon_{t}+\sum_{i=1}^{q} \theta_{q} \varepsilon_{t-i}$

$\operatorname{ARIMA}(\mathrm{p}, \mathrm{d}, \mathrm{q})$ genel denklemi,

$W_{t}=\delta+\phi_{1} W_{t-1}+\phi_{2} W_{t-2}+\ldots+\phi_{p} W_{t-p}+\varepsilon_{t}+\theta_{1} \varepsilon_{t-1}$

$+\theta_{2} \varepsilon_{t-2}+\ldots . \theta_{q} \varepsilon_{t-q}$

Burada

$$
W_{t}, W_{t-1}, W_{t-2}, \ldots, W_{t-p}
$$

değerleri

$Y_{t}, Y_{t-1}, Y_{t-2}, \ldots, Y_{t-p}$ gözlem değerlerinin farkı alınmış hali ve $d$; fark derecesidir (Çağlar 2007, Duru 2007, Sevürtekin ve Nargeleçekenler 2010). Belirlenen modelin uygunluğunu test etmek için Box-Ljung $Q$ testi, $\quad Q=T(T+2) \sum_{i=1}^{k} \frac{r_{T}^{2}}{T-i} \sim \chi_{k-p-q}^{2} \quad$ Box ve Ljung tarafindan tavsiye edilir. Burada, $T$, gözlem sayısı, $k$; otokorelasyon katsayısı, p. dereceden $A R$ ve $q$. dereceden MA derecesidir.. Box-Ljung istatistiği, $\chi^{2}$ tablo değeri ile karşılaştırılır. $Q>\chi_{1-\alpha,(k-p-q)}^{2}$ ise $H_{0}: r_{k}=0$ hipotezi reddedilir. Yani hata terimleri $\varepsilon_{t} \approx i i d\left(0, \sigma^{2}\right)$ dağılımına sahip olmaz ve rassal yürüyüş serisidir (Box ve ark. 2015). Üzerinde çalışılan Laktasyon eğrisi verilerini modellemek için varsaylan matematiksel fonksiyonlar arasından veriye en iyi uyum sağlayanın belirlenebilmesi yada bu varsayılan fonksiyonların veriyi modelleme performanslarını karşılaştırmak için literatürde birçok kriter kullanılmaktadır. Bunlar arasında en yaygın olanları; Belirleme katsayısı $\left(R^{2}\right)$, düzeltilmiş belirleme katsayısı $\left(\mathrm{R}^{2}\right.$ adj), hata kareler ortalaması (Mean square error (MSE)), ortalama mutlak yüzdelik hata (Mean absolute percent error (MAPE)), ortalama mutlak hata (Mean absolute deviation (MAE-MAD)), Akaike bilgi kriteri, bayes bilgi kriteri, Durbin Watson katsayısı, quotient (Q), korelasyon ( $\mathrm{r}$ ) ve WaldWolfowitz run testidir (Wei 2006, Teke ve ark. 2020). $\mathrm{Bu}$ çalışmada laktasyon eğrilerini en iyi modelleyen matematiksel modeli ve veriyi zaman serileri yardımıyla modellendikten sonra tahmin edilen modellerin doğruluğunu belirlemek ve yöntemleri karşılaştırmak için, $\mathrm{R}^{2} ; \sum_{t=1}^{n}\left(\mathrm{Y}_{\mathrm{t}}-\widetilde{\mathrm{Y}}_{\mathrm{t}}\right)^{2} / \sum_{t=1}^{n}\left(\mathrm{Y}_{\mathrm{t}}-\overline{\mathrm{Y}}_{\mathrm{t}}\right)^{2}$, MAPE $; \frac{\sum_{t=1}^{n} \frac{\left|Y_{t}-\tilde{Y}_{t}\right|}{Y_{t}}}{n} 100$, RMSE; $\sqrt{\frac{1}{n} \sum_{t=1}^{n}\left(Y_{t}-\widetilde{Y}_{t}\right)^{2}}$ DurbinWatson; $\frac{\sum_{t=1}^{n}\left(\varepsilon_{t}-\varepsilon_{t-1}\right)^{2}}{\sum_{t=1}^{n} \varepsilon_{t}^{2}}(0<d<4), \mathrm{BIC} ; \ln \left[\frac{1}{n} \sum_{t=1}^{n}\left(Y_{t}-\right.\right.$ $\left.\left.\tilde{Y}_{t}\right)^{2}\right]+\frac{k}{n} \ln n \quad$ kriterleri kullanılmıştır. Burada $\widetilde{Y_{t}}$ tahmin değerleri, $\bar{Y}_{t}$; ortalama değerler, $Y_{t} ; \mathrm{t}$. Zamandaki gözlem değeri $n$; örnek büyüklüğü, $n$ ve $p$; parametre sayısıdır (Schwarz 1978, Neter ve ark. 1990).

\section{İstatistiksel Analizler}

Her laktasyon için; klasik modellemede SAS programında NLMIXED prosedürü kullanılarak modelleme yapılmış ve parametreler tahmin edilmiştir (SAS 2002). Zaman serileri analizlerinde SPSS 21.0 ve E-views paket programı kullanılmıştır (SPSS 2013).

\section{BULGULAR ve TARTIŞMA}

Zaman serileri ve klasik modellerle 80 Holstein sığıra ait dört laktasyon dönemi kontrol günü süt verimleri analiz edilmiştir. Her bir laktasyonda en uygun model belirlenirken, en yüksek $r, R^{2}$, ve en düşük AIC, BIC, RMSE ve MPE değerleri dikkate alınmıştır. Klasik model olarak; üç parametreli Brody, Wood, Cobby Le Du modelleri incelenmiştir. Laktasyon sırasına göre modellerin tahmin parametreleri ve karşılaştırma kriterleri Çizelge 2'de verilmiştir.

Elde edilen sonuçlarda, 1-4 laktasyonda Wood modeli süt verimini en yüksek belirleme katsayısı ile açıklamaktadır. Wood'un geliştirdiği gamma fonksiyonu daha az sapma ile süt verimini tahmin eder. Tahmin modeli ve hataların dağılım grafikleri Şekil 1a-1d'de verilmiştir. Gamma fonksiyonu tahmin denklemleri;

1. laktasyon; $Y_{t}=13.781 t^{0.175} e^{-0.002 t}+\varepsilon_{t}$

2. laktasyon; $Y_{t}=20.3 t^{0.13} e^{-0.003 t}+\varepsilon_{t}$

3. laktasyon; $Y_{t}=19.176 t^{0.174} e^{-0.004 t}+\varepsilon_{t}$

4. laktasyon; $Y_{t}=17.539 t^{0.182} e^{-0.004 t}+\varepsilon_{t}$

Rekik ve ark. (2003), Keskin ve Boztepe (2011), Ural ve Koskan (2014) çalışmalarında Siyah Alaca sığırlarda Wood modelinin süt verim tahmininde etkili olduğunu bildirmişlerdir. Torhizi ve ark. (2019) ve Castillo-Gallegos (2018) Siyah alaca sığırlarda Wood modelini kullanarak süt verimini daha yüksek $\mathrm{R}^{2}$ ile modellemişlerdir. Bangar ve Verma (2017) Duque ve ark. (2018) Brody, Wood ve Cobby Le De modellerini kullandığı çalışmasından daha az hata ile modelleme yapılmıştır.

1-4 laktasyon eğrisinde trend gözlenmiştir. Laktasyon 
serilerinde 16 gecikme için hesaplanan otokorelasyon katsayıları \pm 0.1123 güven aralığı dışındadır. Yüksek otokorelasyon katsayıları daha yüksek gecikmelerde trend yapısındaki gibi zaman içerisinde yavaş azalan bir yapı göstermiştir. $\mathrm{Bu}$ azalış daha sonraki gecikmelerde korelasyon katsayıları anlamsız olana kadar devam etmiştir. Süt verimi serilerinin durağan olmadığ 1 ile ilgili kesin karar vermek için serinin birim kök içerip içermediği ADF-Augmented Dickey Fuller testi ile incelenmiştir.

Çizelge 2. Her bir Laktasyon içim Model tahmin parametreleri ve karşılaştırma kriterleri

Table 2. Model estimation parameters and comparison criteria for each Lactation

\begin{tabular}{|c|c|c|c|c|c|c|c|c|c|c|c|c|c|}
\hline \multirow[b]{2}{*}{$\overbrace{}^{\pi}$} & \multicolumn{13}{|l|}{ Laktasyon } \\
\hline & Model & M1 & M2 & M3 & M1 & M2 & M3 & M1 & M2 & M3 & M1 & M2 & $\overline{\mathrm{M} 3}$ \\
\hline \multirow[t]{3}{*}{$\mathrm{a}$} & Estimate & 26.07 & 13.78 & 25.84 & 31.88 & 20.30 & 31.16 & 35.29 & 19.18 & 33.79 & 33.67 & 17.54 & 32.10 \\
\hline & & 163.76 & 63.14 & 185.51 & 213.87 & 70.69 & 264.86 & 165.74 & 60.863 & 216.21 & 126.18 & 43.19 & 158.29 \\
\hline & $\operatorname{Pr}>|t|$ & 0.000 & 0.000 & 0.000 & 0.000 & 0.000 & 0.000 & 0.000 & 0.000 & 0.000 & 0.000 & 0.000 & 0.000 \\
\hline \multirow[t]{3}{*}{ b } & Estimate & 0.001 & 0.175 & 0.023 & 0.002 & 0.130 & 0.044 & 0.002 & 0.174 & 0.059 & 0.002 & 0.182 & 0.056 \\
\hline & 18 & 29.85 & 37.94 & 31.01 & 61.83 & 30.60 & 67.79 & 62.96 & 35.06 & 69.28 & 48.43 & 26.12 & 50.46 \\
\hline & $>1 t \mid$ & 0.000 & 0.000 & 0.000 & & 0.000 & 0.000 & 0.000 & 0.000 & 00 & & 0.000 & 0.000 \\
\hline \multirow[t]{3}{*}{ c } & te & 0.163 & 0.002 & 0 . & & 0.0 & $0.3^{2}$ & 0.199 & 04 & 33 & 64 & 0.004 & 0.192 \\
\hline & & 21.71 & 49.47 & 22.19 & 21 & 59.76 & 22 & 21.76 & 09 & 49 & 19.07 & 48.04 & 17.69 \\
\hline & $\operatorname{Pr}>|t|$ & 0.000 & 0.000 & 0.000 & 0 & 0.000 & 0.0 & 0.000 & 0.000 & 00 & 0.000 & 0.000 & 0.000 \\
\hline \multirow{11}{*}{ 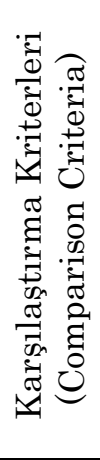 } & $\mathrm{r}$ & 0.916 & 0.951 & 0.92 & 0.968 & 0.977 & $0 . \subseteq$ & 0.971 & 0.982 & 73 & 0.953 & 0.965 & 0.952 \\
\hline & $\mathrm{S}^{2}$ & 1.02 & 0.49 & 0.98 & 0.96 & 0.67 & 0.85 & 1.52 & 0.91 & 1.39 & 2.16 & 1.56 & 2.20 \\
\hline & $\mathrm{IIC}$ & 878.3 & 656.2 & 866 & 860.6 & 752.5 & 822.7 & 1000 & 844.7 & 973.3 & 1109 & 1010 & 1113.2 \\
\hline & BIC & 893.2 & 671.1 & 880.9 & 875.5 & 767.4 & 837.6 & 1015.3 & 859.6 & 988.2 & 1123.9 & 1024.9 & 1128.8 \\
\hline & myh & 78 & 2.45 & 55 & 2.61 & 2.49 & 2.42 & 3.32 & 12 & 38 & 4.29 & 4.43 & 4.60 \\
\hline & $\mathrm{mh}$ & & 3 & & 0.62 & 0.60 & & 0.79 & 0.73 & 9 & 7 & 00 & 1.04 \\
\hline & $\mathrm{ME}$ & -0 & 0.00 & -0 & -0.02 & -0.00 & -0.02 & -0.04 & -0.01 & -0.04 & -0.06 & -0.01 & -0.05 \\
\hline & MPI & -0.33 & 1 & -0.33 & -0.05 & 0.05 & -0.08 & -0.09 & -0.01 & -0.13 & -0.18 & 0.06 & -0.14 \\
\hline & RMSE & 1. & 0.70 & 0.99 & 0.98 & 0.82 & 0.92 & 1.23 & 0.95 & 1.18 & 1.47 & 1.25 & 1.48 \\
\hline & $\mathrm{R}^{2}$ & 0.84 & 0.92 & 0.85 & 0.94 & 0.96 & 0.95 & 0.94 & 0.97 & 0.95 & 0.90 & 0.93 & 0.90 \\
\hline & $\mathrm{R}^{2}$ & 84 & 92 & 84 & 0.94 & 96 & 95 & .94 & 0.97 & .95 & .90 & 0.93 & 0.90 \\
\hline
\end{tabular}
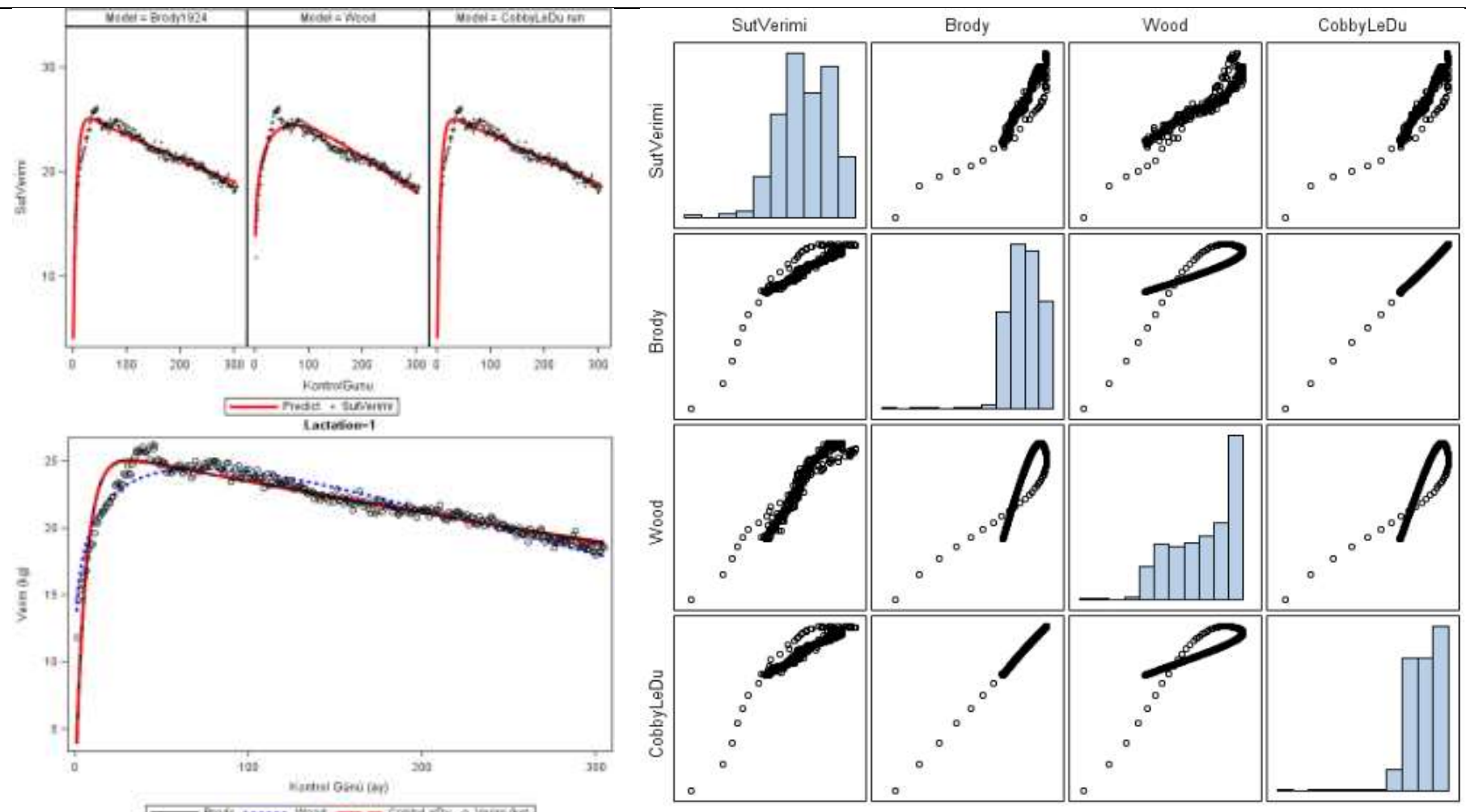

Şekil 1a. 1. laktasyonda tahmin modeli ve hataların dağglım grafikleri

Figure1a. Forecast model and scatter plots of errors in 1. lactation 

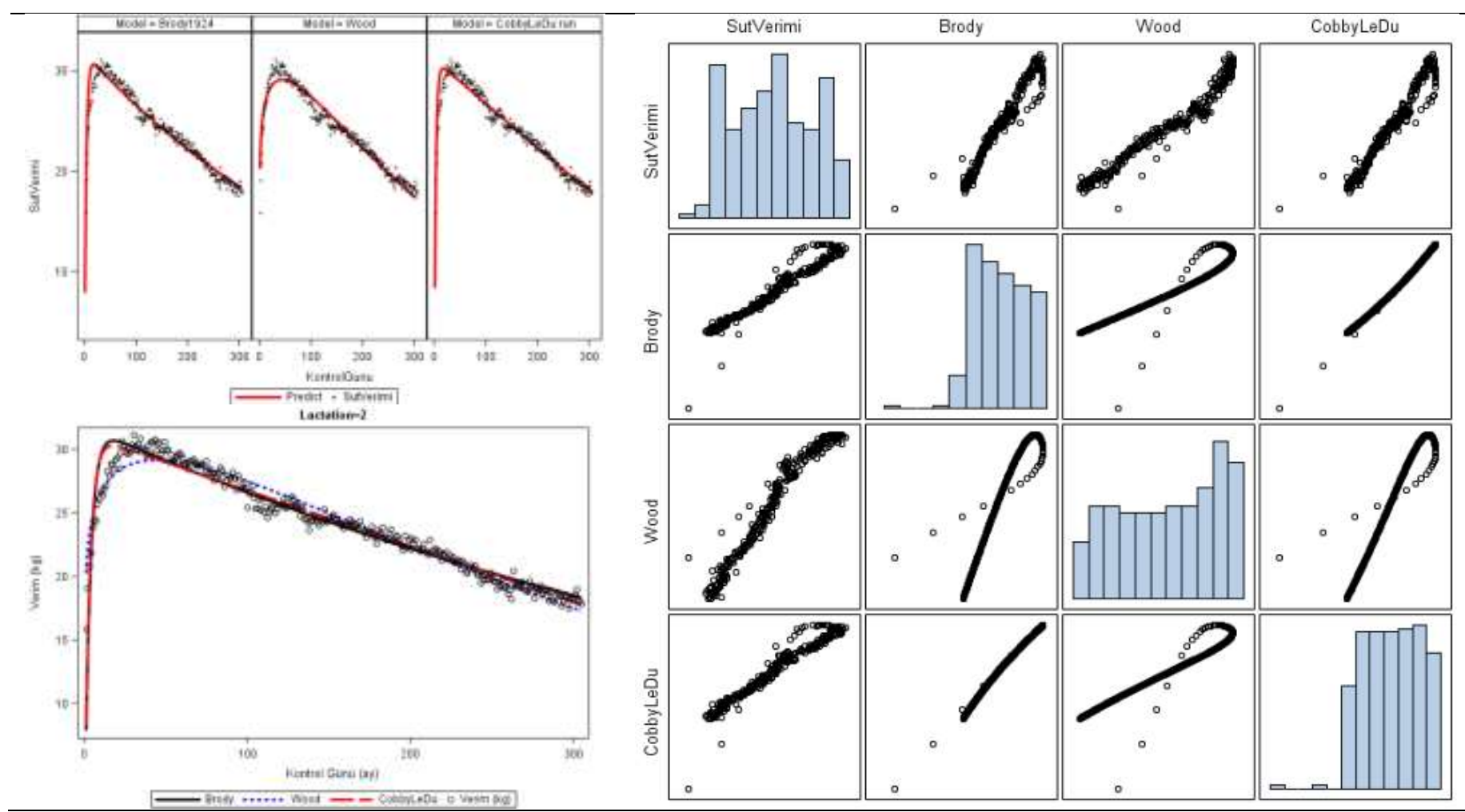

Şekil 1b. 2. laktasyonda tahmin modeli ve hataların dağglım grafikleri

Figure 1b. Forecast model and scatter plots of errors in 2. lactation
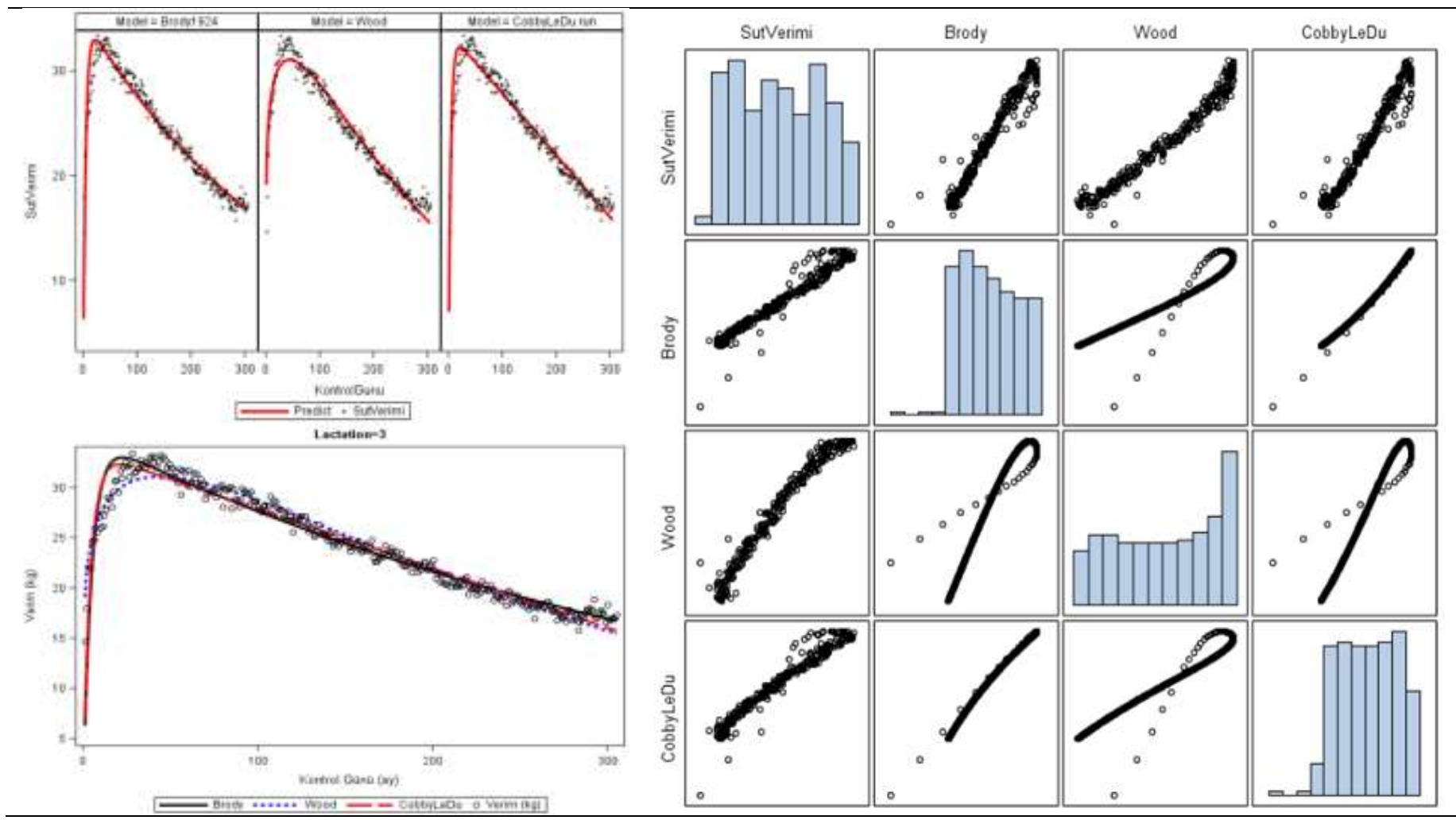

Şekil 1c. 3. laktasyonda tahmin modeli ve hataların dağılım grafikleri

Figure 1c. Forecast model and scatter plots of errors in 3. lactation 

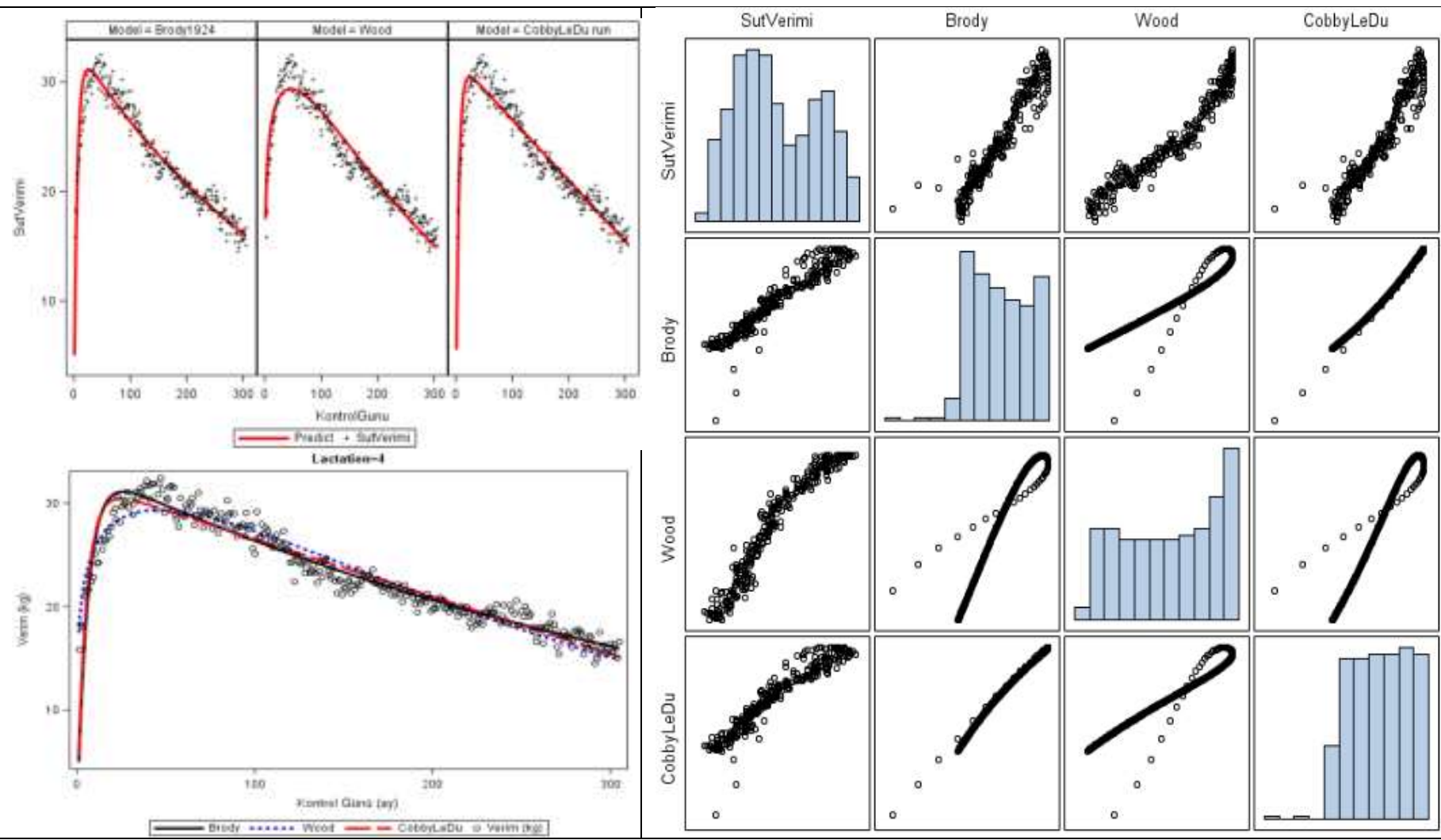

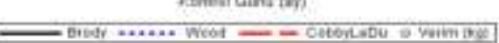

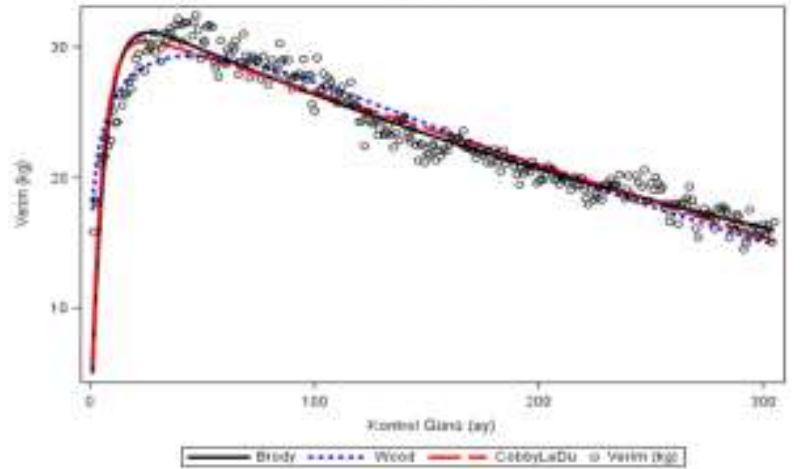

Şekil 1d. 4. laktasyonda tahmin modeli ve hataların dağglım grafikleri

Figure1d. Forecast model and scatter plots of errors in 4. lactation

ADF sonuçları $\left(\tau^{\wedge}=-0.015017\right),\left(\tau^{\wedge}=1.4355\right),\left(\tau^{\wedge}=\right.$ $0.214923),\left(\tau^{\wedge}=-0.04697\right),\left(\tau^{\wedge}=-0.645117\right) \% 1, \% 5$ ve $\% 10$ değerlerinden büyük ve $\mathrm{p}>0.05$ olduğundan seriler birim köklü yani durağan değildir. Bu sebeple seriye birinci dereceden fark işlemi uygulanarak seri trendden arındırılıp durağan hale getirilmiştir. ACF, PACF ve ADF sonuçları farkı alınmış serilerin durağan olduğunu göstermektedir. ARIMA modelleri için $d=1$ için $A C F$ ve PACF grafikleri Şekil 2'de verilmiştir. İki gecikmeye kadar denenen ARIMA modelleri içinden süt verimi tahmini için en uygun modeller Çizelge 3 'te belirtilmiştir.

Box-Ljung Q test değerleri tüm laktasyonlar için rastgele dağılım göstermektedir ( $p>0.05)$. ARIMA modelleri sirasiyla \% 97.58,\% 98.52,\% 98.57,\% 96.88,\% 93.14 süt verimini açıklamaktadır. ARIMA modelleri tahmin parametrelerin önemi ve geçerliliği incelendiğinde; Kolmogorov-Smirnov değeri $(p=0.200)$ kalıntıların normal dağılıma sahip olduğu ve Run (Swed-Eisenhart) test istatistiği model artıkların bağımsız ve homojen olduğu görülmektedir. Model artıklarının ACF ve PACF değerleri, artıklar güven sinırları içinde olduğundan beyaz gürültü serisine sahiptir. 305 gözlemli ve 1 bağımsız değişkenli laktasyon serilerinde Durbin Watson değeri $\rho=0$ bölgesinde olup otokorelasyon problemi yoktur. Yani artıklar arasında birinci dereceden ardışık bir ilişki olmadığı söylenebilir. Laktasyon sırasına göre model artıklarının ACF ve PACF grafikleri ve model tahmin grafikleri şekil 2'de verilmiştir. ARIMA model denklemleri;

1. laktasyon için ARIMA $(1,1,2)$ model,

$\nabla Y_{t}=\delta+\phi_{1} Y_{t-1}+\varepsilon_{t}+\theta_{1} \varepsilon_{t-1}+\theta_{2} \varepsilon_{t-2}$

$\nabla Y_{t}=-0.002+0.994 Y_{t-1}+\varepsilon_{t}+1.353 \varepsilon_{t-1}-0.426 \varepsilon_{t-2}$

2. laktasyon için ARIMA $(2,1,0)$ model,

$\nabla Y_{t}=\delta+\phi_{1} Y_{t-1}+\phi_{2} Y_{t-2}+\varepsilon_{t}$

$\nabla Y_{t}=-0.032-0.471 Y_{t-1}-0.232 Y_{t-2}+\varepsilon_{t}$

3. laktasyon için ARIMA $(1,1,2)$ model,

$\nabla Y_{t}=\delta+\phi_{1} Y_{t-1}+\varepsilon_{t}+\theta_{1} \varepsilon_{t-1}+\theta_{2} \varepsilon_{t-2}$

$\nabla Y_{t}=-0.028-0.897 Y_{t-1}+\varepsilon_{t}-0.469 \varepsilon_{t-1}+0.429 \varepsilon_{t-2}$

4. laktasyon için ARIMA $(1,1,2)$ model,

$\nabla Y_{t}=\delta+\phi_{1} Y_{t-1}+\varepsilon_{t}+\theta_{1} \varepsilon_{t-1}+\theta_{2} \varepsilon_{t-2}$

$\nabla Y_{t}=-0.023-0.974 Y_{t-1}+\varepsilon_{t}-0.427 \varepsilon_{t-1}+0.567 \varepsilon_{t-2}$

Siyah Alaca ırkı sığırlarda ARIMA modelinin gamma fonksiyonuna göre her bir laktasyon için kontrol günü süt verimleri tahmininde etkilidir. Benzer sonuçları Siyah Alaca sığırlarda Deluyker ve ark. (1990) ve Wade ve ark. (1993), bulmuşlardır. Macciotta ve ark. (2000), Sarda koyunlarında da ARIMA'nin, laktasyon eğrisinin tanımlanması ve her bir laktasyon dönemi içerisindeki aylık kontrol günü süt verimleri tahmininde etkili olduğunu bildirmişlerdir. Macciotta ve ark. (2002), İtalyan Simmental ırkı sığırlarda ARMA'nın laktasyon verimi öngörüsünde daha karmaşık modellere kıyasla önemli sonuçlar verdiği ve 
oldukça kolay uygulandığını bildirmişlerdir. Sankar ve Prabakaran (2012) ve Chaudhari ve Tingre (2013), süt üretimini modellemişler ve benzer şekilde en uygun modeli ARIMA model olarak bildirmişlerdir.

Çizelge 3. Zaman serilerinde tahmin parametreleri ve karşılaştırma kriterleri

Table 3. Estimation parameters and comparison criteria in time series

\begin{tabular}{lcccc}
\hline Laktasyon (Lactation) & 1 & 2 & 3 & 4 \\
\hline Model & ARIMA & ARIMA & ARIMA & ARIMA \\
$(1,1,2)$ & $(2,1,0)$ & $-1,1,2)$ & -0.023 \\
\hline Kesme (intercept) & -0.002 & -0.032 & -0.028 & 0.269 \\
$\mathrm{P}$ & 0.807 & 0.047 & 0.155 & -0.974 \\
$\mathrm{~d}_{1}$ & 0.994 & -0.471 & -0.897 & 0.000 \\
$\mathrm{P}$ & 0.000 & 0.000 & 0.000 & -0.427 \\
$\theta_{1}$ & 1.353 & & -0.469 & 0.000 \\
$\mathrm{P}$ & 0.000 & & 0.001 & \\
$\mathrm{~d}_{2}$ & & -0.232 & & 0.567 \\
$\mathrm{P}$ & & 0.000 & 0.429 & 0.000 \\
$\theta_{2}$ & -0.426 & & 0.000 & 0.9688 \\
$\mathrm{P}$ & 0.000 & & 0.9857 & 14.339 \\
$\mathrm{R}^{2}$ & 0.9758 & 0.9852 & 0.9857 & 0.500 \\
$\mathrm{R}^{2}$ adj & 0.9757 & 0.9851 & 12.125 & 2.956 \\
Ljung-Box Q(sig.) & 16.551 & 18.105 & 0.670 & 0.846 \\
MAPE & 0.353 & 0.318 & 2.060 & -0.259 \\
RMSE & 1.233 & 1.634 & 0.613 & 0.200 \\
BIC & 0.338 & 0.389 & -0.945 & 0.301 \\
Kolmogrov-Smirnov (p) & -2.093 & -1.414 & 0.200 & \\
Run (Swed-Eisenhart)(p) & 0.200 & 0.200 & 0.414 & 2.023 \\
DW & 0.909 & 0.730 & & 0.984 \\
(1.779<DW<2.221) & & & 1.923 & \\
$\mathrm{r}$ & 1.975 & 1.979 & 0.993 & \\
\hline
\end{tabular}

R2: Belirleme katsayısi; RMSE: Hata kareler ortalamasının karekökü;

MAPE: Ortalama mutlak hata orani; r: Korelasyon katsayısi; DW: Durbin Watson

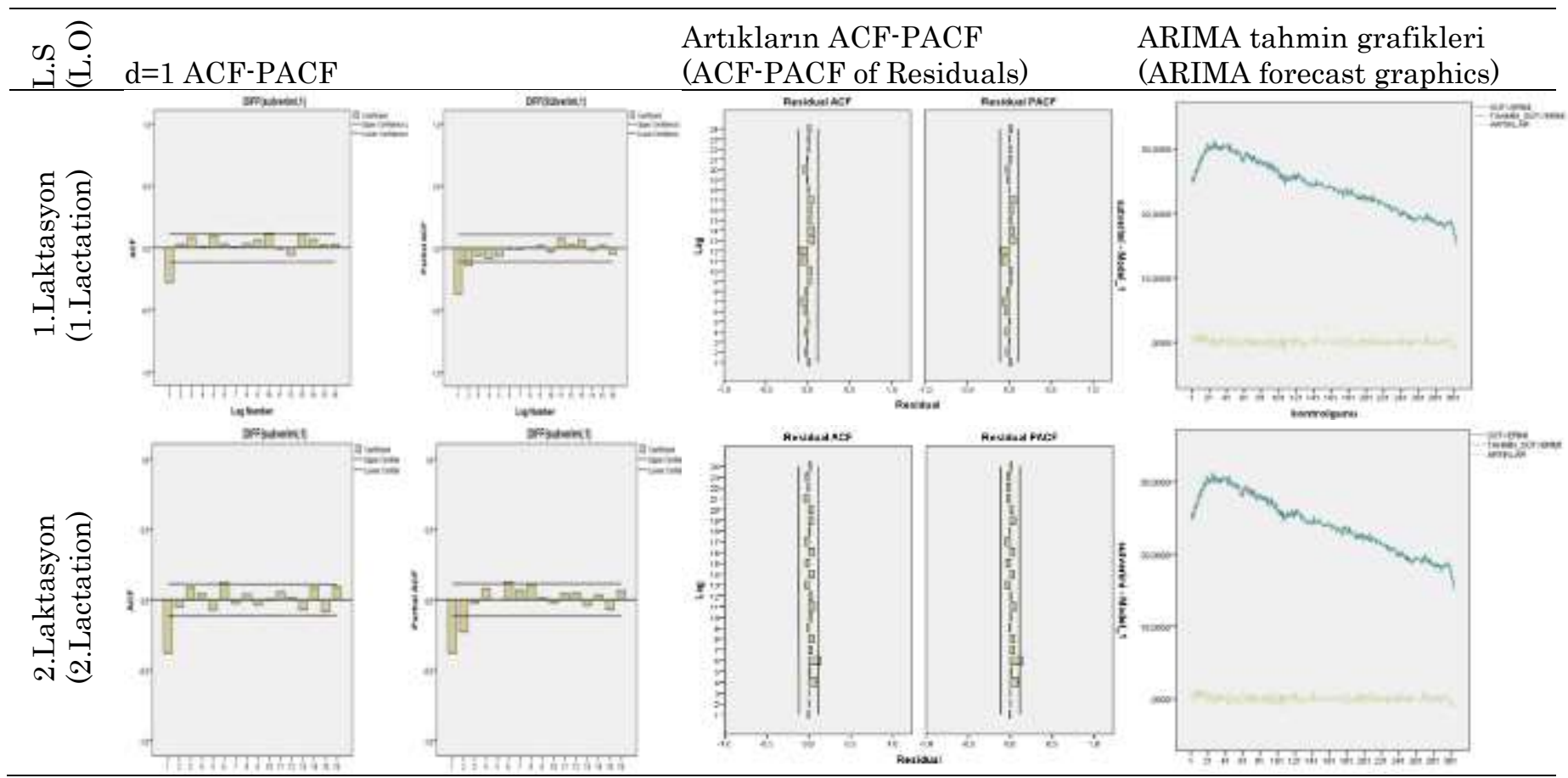

Şekil 2. ARIMA model grafikleri ve artıkların ACF-PACF grafikleri

Figure 2. ARIMA model graphics and ACF-PACF graphics of residuals 


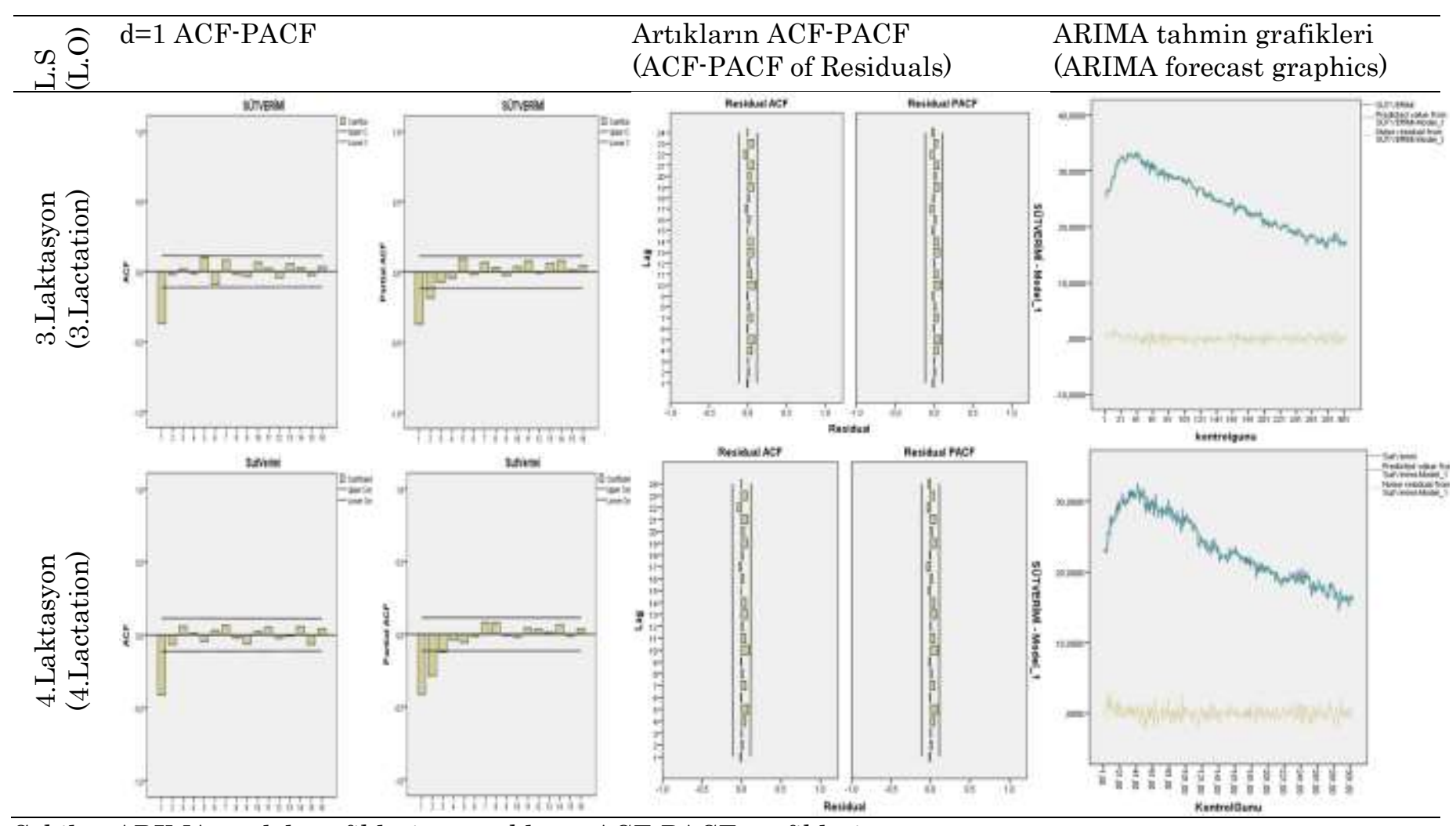

Şekil 2. ARIMA model grafikleri ve artıkların ACF-PACF grafikleri

Figure 2. ARIMA model graphics and ACF-PACF graphics of residuals

\section{SONUÇ ve ÖNERİLER}

Laktasyon eğrileri modellemesi değerlendirildiğinde; Brody, Wood ve Cobby Le De'nun geliştirdiği laktasyon eğrisi modellerinden gamma fonksiyonu tüm laktasyonlarda kontrol günü süt verimini en az sapma, en yüksek korelasyon ve belirleme katsayısı ile açıklamıştır. Birinci laktasyon için; gamma fonksiyonu kontrol günü süt verimini \%92 oranında açıklarken zaman serileri yöntemi kontrol günü süt verimini \%97.57 oranında açıklamaktadır. İkinci laktasyon için; süt verimini gamma fonksiyonu $\% 96$ oranında, ARIMA $(2,1,0)$ modeli \%98.5 oranında açıklamaktadır. $\operatorname{ARIMA}(2,1,0)$ modeli artıkları normal dağılıma sahipken $(\mathrm{p}>0,05)$ Gamma model artıkları normal dağılıma sahip değildir $(p<0,05)$. Korelasyon katsayısı gamma fonksiyonu için 0.968 iken $\operatorname{ARIMA}(2,1,0)$ modeli için 0.993'tür. Üçüncü laktasyon için; süt verimini gamma fonksiyonu $\% 97$ oraninda, ARIMA $(1,1,2)$ modeli \%98.6 oranında açıklamaktadır. Gamma ve ARIMA $(1,1,2)$ model artıkları normal dağılmaktadır $(\mathrm{p}>0,05)$. Korelasyon katsayısı gamma fonksiyonu için 0.971 iken $\operatorname{ARIMA}(1,1,2)$ modeli için 0.993 'tür. Dördüncü laktasyon için; süt verimini gamma fonksiyonu \%93 oranında açıklarken ARIMA(1,1,2) \%96.9 oranında açıklamaktadır. Gamma ve ARIMA(1,1,2) modeli artıkları normal dağılmaktadır $(\mathrm{p}>0,05)$. Korelasyon katsayısı gamma fonksiyonu için 0.965 iken $\operatorname{ARIMA}(1,1,2)$ modeli için 0.984'tür. Tüm laktasyon dönemleri için; MAPE, RMSE, BIC değerleri gamma fonksiyonunda zaman serilerine göre daha yüksek çıkmıştır. ARIMA model artıklarının otokorelasyon grafiğinden beyaz gürültü serisi olduğu ve Box-Ljung testine göre modellerin uygun model olduğu görülmüştür. DW değeri gamma fonksiyonlarında pozitif otokorelasyon bölgesinde iken ARIMA modellerinde $\rho=0$ bölgesinde olup model artıkları rasgele dağılmaktadır.

Laktasyon eğrisi modellemesinde zaman serisi yöntemi kullanılarak hayvanın mevcut süt verim kayıtlarından ileriki dönemde vereceği süt miktarı ve laktasyon eğrisinin şekli gerçek süt verim değerlerine daha yakın tahmin edilebileceği sonucuna ulaşılmıştır. Siyah Alaca sığırlarının laktasyon eğrisi tahmininde kullanılacak uygun tahmin modelleri ile süt verimini artırmaya yönelik ıslah programları, süt üretim işletmelerinin kârının artmasını sağlayacaktır. Ülkemizdeki çok sayıda süt üretim işletmelerini ve artan kâr payını göz önüne aldığımızda, doğrusal olmayan yapilara uygun tahmin modellerinin ulusal ekonomiye, toplumsal refaha ve aynı zamanda literatüre katkı sağlayacağı düşünülmektedir. Bu sebeple zaman serisi yöntemi süt verimi yüksek ırklarda veya koyun, keçi, manda gibi farklı hayvanların süt verim modellemesinde kullanılabilir. Ayrıca ekonomik olarak yetiştiriciliği yapılan hayvanların et verimi; hayvan ve yumurta sayılarını modellemek için kullanılabilir. Kısaca birçok hayvan türünden elde edilecek ürünlerin modellemesinde zaman serisi yönteminin kullanışlı olacağı önerilmektedir. 


\section{TEŞEKKÜR}

Bu çalışma SDÜ Fen Bilimleri Zootekni Anabilim dalında yürütülen doktora tez çalışmasından kısmen özetlenmiştir. Tez çalışması 2211-C yurtiçi öncelikli alanlar doktora burs programı ile TÜBİTAK'tan maddi destek almıştır.

\section{Araştırmacıların Katkı Oranı Beyan Özeti}

Yazarlar makaleye eşit oranda katkı sağlamış olduklarını beyan eder.

\section{Çıkar Çatışması Beyanı}

Makale yazarları aralarında herhangi bir çıkar çatışması olmadığını beyan ederler.

\section{KAYNAKLAR}

Akdi Y 2010. Zaman Serileri Analizi (Birim Kökler ve Kointegrasyon). Gazi Kitabevi, 2. Baskı, Ankara, 393 sy.

Anonim 2017 Hayvancılık Sektör Raporu, Tarım İşletmeleri Genel Müdürlüğü, https://www.tigem. gov.tr/ (Erişim tarihi :10.11. 2018)

Bangar YC, Verma MR 2017. Non-linear Modelling to Describe Lactation Curve in Gir Crossbred Cows. Journal of Animal Science and Technology 59(3): 17.

Box GE, Jenkins GM, Reinsel GC, Ljung GM 2015. Time Series Analysis: Forecasting And Control. John Wiley Sons, 5th Edition, Hoboken, $712 \mathrm{pp}$.

Bozkurt H 2013. Zaman Serileri Analizi. Ekin Kitapevi Yayınları, İstanbul, 261 sy.

Brody S, Turner CW, Ragsdale AC 1924. The Relation Between The Initial Rise and The Subsequent Decline of Milk Secretion Following Parturition. The Journal of General Physiology 6(5): 541.

Castillo-Gallegos E 2018. Characterization of The Lactation Curve of F1 Holstein-Zebu Cows. Ecosistemas y Recursos Agropecuarios 5(14): 335343.

Chaudhari D, Tingre A 2013. Forecasting of Milk Production in India: An Application of ARIMA Model. Indian J Dairy Science 66: 72-78.

Cobby J, Le Du Y 1978. On Fitting Curves to Lactation Data. Animal Science, 26(2): 127-133.

Çağlar T 2007. Talep Tahmininde Kullanılan Yöntemler ve Fens Teli Üretimi Yapan Bir İşletmede Uygulanması. Kırıkkale Üniversitesi Fen Bilimleri Enstitüsü Endüstri Mühendisliği Anabilim Dalı, Yüksek Lisans Tezi, 117 sy.

Deluyker H, Shumway R, Wecker W, Azari A, Weaver L 1990. Modeling Daily Milk Yield in Holstein Cows Using Time Series Analysis. Journal of Dairy Science 73(2): 539-548.

Duque NP, Casellas J, Quijano JH, Casals R, Such X 2018. Fitting Lactation Curves in a Colombian
Holstein Herd Using Nonlinear Models. Revista Facultad Nacional de Agronomía Medellín 71(2): 8459-8468.

Duru Ö 2007. Zaman Serileri Analizinde ARIMA Modelleri ve Bir Uygulama. İstanbul Üniversitesi Sosyal Bilimler Enstitüsü Ekonometri Anabilim Dal, Yüksek Lisans Tezi, 103 sy.

France J, Kebreab E 2008. Mathematical Modelling in Animal Nutrition. CAB International, Oxfordshire Cambridge, UK, 640 sy.

Göktaş Ö 2005. Teorik ve Uygulamalı Zaman Serileri Analizi. Beşir Kitabevi, İstanbul, 161 sy.

Kadılar C 2005. SPSS Uygulamalı Zaman Serileri Analizine Giriş. Ankara, 299 sy.

Keskin I, Boztepe S 2011. Siyah Alaca Sığırlarda Kismi Süt Verimlerinden Yararlanılarak 305 Günlük Süt Veriminin Tahmini. Journal of Tekirdag Agricultural Faculty 8(1): 1-7.

Keskin I, Tozluca A 2004. Süt Sığırlarında Laktasyon Eğrilerinin Farklı Matematik Modellerle Belirlenmesi Ve Kontrol Aralığının Tespiti. Selçuk Tarım Bilimleri Dergisi 18(34): 11-19.

Macciotta NPP, Cappio-Borlino A, Pulina G 2000. Time Series Autoregressive Integrated Moving Average Modeling of Test-Day Milk Yields of Dairy Ewes. Journal of Dairy Science 83(5): 1094-1103.

Macciotta NPP, Vicario D, Pulina G, Cappio-Borlino A 2002. Test Day and Lactation Yield Predictions in Italian Simmental Cows by ARMA Methods. Journal of Dairy Science 85(11): 3107-3114.

Murat H, Sakarya E 2012. Orta Anadolu Bölgesi Damızlık Sığır Yetiştirici Birliklerine Bağlı Süt Sığırcılık İşletmelerinin Ekonomik Analizi. Veteriner Hekimler Derneği Dergisi 83(1): 5-14.

Neter J, Wasserman W,Kutner MH 1990. Applied Linear Statistical Models. Homewood, 3rd ed. IL: Irwin, $673 \mathrm{pp}$.

Orhan H, Kaygisız A 2002. Siyah Alaca Siğırlarda Farklı Laktasyon Eğrisi Modellerinin Karşılaştırılması. Hayvansal Üretim 43(1): 94-99.

Rekik B, Gara AB, Hamouda MB, Hammami H 2003. Fitting Lactation Curves of Dairy Cattle in Different Types Of Herds in Tunisia. Livestock Production Science 83: 309-315.

Sankar T, Prabakaran R 2012. Forecasting Milk Production in Tamilnadu. International Multidisciplinary Research Journal 2(10): 10-15.

SAS (2002) SAS Institute. In:9.1 ed. for Windows. SAS/STAT user's guide. Cary, NC, USA.

Schwarz G 1978. Estimating The Dimension of a Model. The Annals of Statistics 6: 461-464.

Sevürtekin M, Nargeleçekenler M 2010. Ekonometrik Zaman Serileri Analizi Eviews Uygulamalı. Nobel Yayınları, 3. Baskı, Ankara, 592 sy.

SPSS 2013. IBM SPSS Statistics 21.0 for Windows. Armonk, NY.

Teke EÇ, Firat MZ, Yardibi F 2020. A Comprehensive Review of Lactation Curves in Dairy Cattle. 
(Visional Studies in Agricultural and Aquatic Science, Akademisyen Kitabevi, TURKEY: Ed. Yücel B, Tolon MT) 19-41.

Torhizi ME, Mashhadi MH, Farhangfar H 2019. Different Aspects of Lactation Persistency in Dairy Cows. Indian Journal of Animal Sciences 89(6): 607614.

Ural DA, Koskan O 2014. The Estimation of Lactation Curve Parameters From Test Day Milk Yield in Holstein-Friesian Cows in Bozdogan Province in Turkey. Res J Agric Environ Manag 3(2): 145-150.

Wade K, Quaas R, Van Vleck LD 1993. Estimation of The Parameters Involved in a First-Order
Autoregressive Process For Contemporary Groups. Journal of Dairy Science 76(10): 3033-3040.

Wei WWS 2006. Time Series Analysis, Univariate and Multivariate Methods. Addison Wesley Publishing Company.

Wood P 1967. Algebraic Model of The Lactation Curve in Cattle. Nature 216(5111): 164-165.

Yıldız D 2009. Zaman Serileri Analizi Ve Yapay Sinir Ağları İle Tahmin: Yabancı Portföy Yatırımları Üzerine Uygulama. Ankara Üniversitesi Sosyal Bilimler Enstitüsü, İşletme Anabilim Dalı, Doktora Tezi, 216 sy. 